\title{
Gastric atrophy and oesophageal squamous cell carcinoma: possible interaction with dental health and oral hygiene habit
}

\section{Nasrollahzadeh ${ }^{1,2}, \mathrm{R}$ Malekzadeh ${ }^{*, 2}, \mathrm{~K}$ Aghcheli $^{2}$, M Sotoudeh $^{2}, \mathrm{~S}$ Merat $^{2}, \mathrm{~F}$ Islami $^{2,3}, \mathrm{~F} \mathrm{Kamangar}{ }^{2,4}$, CC Abnet ${ }^{5}$, R Shakeri ${ }^{2}$, A Pourshams ${ }^{2}$, S Semnani ${ }^{6}$, P Boffetta $^{3}$, SM Dawsey and W Ye,,}

'Department of Medical Epidemiology and Biostatistics, Karolinska Institutet, Stockholm 17177, Sweden; ${ }^{2}$ Digestive Disease Research Center, Tehran University of Medical Sciences, North Karegar Ave., Tehran 14117, Iran; ${ }^{3}$ Institute for Translational Epidemiology and Tisch Cancer Institute, Mount Sinai School of Medicine, New York, NY 10029-6574, USA; ${ }^{4}$ Department of Public Health Analysis, School of Community Health and Policy, Morgan State University, Baltimore, MD 2125I, USA; ${ }^{5}$ Division of Cancer Epidemiology and Genetics, National Cancer Institute, Bethesda, MD 20892-7335, USA; ${ }^{6}$ Golestan Research Center of Gastroenterology and Hepatology, Gorgan University of Medical Sciences, Gorgan 49175-1141, Iran

BACKGROUND: Gastric fundal atrophy has been hypothesised to increase the risk of oesophageal squamous cell carcinoma (OSCC), but studies have shown inconsistent results.

METHODS: We measured serum pepsinogen I (PGI) and pepsinogen II (PGII) among 293 incident cases and 524 matched neighbourhood controls in a high-risk area of Northern Iran. Conditional logistic regression model was used to estimate odds ratios (ORs) and their 95\% confidence intervals $(\mathrm{Cls})$.

RESULTS: After controlling for age, sex, residence area and other potential confounders, gastric atrophy (defined by a validated criterion, $\mathrm{PGl}<55 \mu \mathrm{g} \mathrm{dl}^{-1}$ ) was associated with a two-fold increased risk $(\mathrm{OR}=2.01,95 \% \mathrm{Cl}$ : I. I 8, 3.45) of OSCC in the absence of nonatrophic pangastritis (defined as PGIl $<11.8 \mu \mathrm{g} \mathrm{dl}^{-1}$ ). Stratification by PGll decreased the misclassification errors due to cancerinduced gastritis. Presence of both poor dental health, indicated by higher than median sum of decayed, missing, and filled teeth (DMFT score), and gastric atrophy further increased the risk of OSCC (OR $=4.15,95 \% \mathrm{Cl}: 2.04,8.42)$ with relative excess risk due to interaction (RERI) of $1.47(95 \% \mathrm{Cl}:-1.15,4.1)$. Coexistence of poor oral hygiene habit with gastric atrophy elevated OSCC risk eight times ( $\mathrm{OR}=8.65,95 \% \mathrm{Cl}: 3.65,20.46)$ and the additive interaction index was marginally statistically significant $(\mathrm{RERI}=4.34$, $95 \% \mathrm{Cl}:-1.07,9.76)$.

CONCLUSION: Gastric atrophy is a risk factor for OSCC, and poor dental health and oral hygiene habit may act synergistically in increasing the risk.

British Journal of Cancer (2012) 1 07, 888-894. doi:I0.1038/bjc.2012.332 www.bjcancer.com

Published online 19 July 2012

(c) 2012 Cancer Research UK

Keywords: atrophic gastritis; oesophageal neoplasm; relative risk; dental health; oral hygiene; pepsinogen

Oesophageal cancer is the eighth most common cause of cancer death worldwide (Jemal et al, 2011). Gastric atrophy as a consequence of chronic Helicobacter pylori infection was linked to an increased risk of oesophageal squamous cell carcinoma (OSCC) in a Swedish population-based case-control study (Ye et al, 2004). In the atrophic stomach, hypochlorohydria allows bacterial overgrowth (Viani et al, 2000) and may produce potential carcinogenic substances, such as nitrosamines, which are also related to alcohol drinking and tobacco smoking (Millonig et al, 2011). Histology is the gold standard for diagnosing gastric atrophy. However, because of its inconvenience in large epidemiological studies, serum level of pepsinogens has been applied as a replacement method. Pepsinogen I (PGI) is produced in the fundic glands and decreases proportionally with progression of fundic atrophy. Pepsinogen II (PGII) is synthesised in most

*Correspondence: Professor R Malekzadeh; E-mail: malek@ams.ac.ir or Professor W Ye; E-mail: weimin.ye@ki.se

Received 12 April 2012; revised 29 June 2012; accepted 5 July 2012; published online 19 July 2012 parts of the gastric mucosa and part of the duodenum and some studies have shown its importance in detecting inflammation (He et al, 2011) or gastric cancer screening (Abnet et al, 2011). Magnitude of the reported associations between serological gastric atrophy and OSCC varied from null to eightfold (Iijima et al, 2007; de Vries et al, 2009; Ren et al, 2009; Cook et al, 2010; Venerito et al, 2011).

Poor oral and dental hygiene are also linked to nitrosamine (Meurman and Uittamo, 2008) and acetaldehyde production (National Toxicology Program, 2010). In addition, poor oral hygiene and dental health have been shown to be associated with an increased risk of OSCC in high-risk areas (Abnet et al, 2001, 2008). Previous studies have not tested possible synergism between these two risk factors. Golestan province in Iran is located in the Asian Oesophageal Cancer Belt and has some of the highest incidence rates for OSCC (Mahboubi et al, 1973; Saidi et al, 2000). Unlike low-risk areas, tobacco and alcohol use are not major risk factors for OSCC in this belt (Nasrollahzadeh et al, 2008), from which $90 \%$ of the OSCC cases arise worldwide. We evaluated the association between gastric atrophy (measured by serum pepsinogen level) and OSCC in a population-based case-control 
study in Northern Iran and tested joint effect on OSCC risk in the presence of both gastric atrophy and poor oral hygiene.

\section{MATERIALS AND METHODS}

\section{Case and control selection}

Details of subject selection have been reported earlier (Nasrollahzadeh et al, 2008). Briefly, case subjects were recruited at Atrak clinic, the only specialised clinic for oesophageal cancer diagnosis and treatment in eastern Golestan, from December 2003 to June 2007. Included cases were those of histopathologically confirmed OSCC patients who underwent oesophago-gastroduodenal videoscopy at Atrak clinic and agreed to participate in the study. The reports of the local cancer registry demonstrated that $\sim 70 \%$ of all incident cases during the study period were referred to Atrak clinic (unpublished data). Attempts were made to select two population-based control subjects, individually matched to the cases by age ( \pm 2 years), sex, and from the same neighbourhood or village using annually updated family health census. List of all potentially eligible controls for rural cases was ordered randomly in each village and for urban cases was ordered by geographic proximity to the case's residence. In all, $77 \%$ of the enrolled controls were the first selected neighbours, and $11 \%$ and $3 \%$, respectively, were the second and third choices from the lists. Absence of the eligible control at the time of invitation was almost always the reason for not participating in the study. In total, we recruited 300 cases and 571 matched controls.

To investigate whether OSCC cases have higher risk of developing non-atrophic gastritis in histology, we used another set of controls. Controls were consisted of endoscopy room patients who were referred to Atrak clinic with a suspicion of upper gastrointestinal malignancies during same period of case enrolment and were matched for age and sex. Three biopsy tissues from lesser-curvature antrum, lesser-curvature body and cardia were available for 261 cases $(88 \%)$ and 274 controls.

\section{Interview and examination}

After obtaining written informed consent from each subject, a nurse and a physician administered a structured questionnaire. A nutritionist administered a validated food frequency questionnaire (Malekshah et al, 2006). All interviews were conducted face to face at Atrak clinic for case subjects and at health centres for controls except those chosen from Gonbad city who were interviewed at Golestan Cohort Centre. No proxies were used.

The trained physicians examined each patient's oral cavity and teeth. Number of decayed, missing, and filled teeth (DMFT score) in addition to frequency of tooth brushing was recorded. Detailed information has been published elsewhere (Abnet et al, 2008). Reliability of measuring tooth count using $\kappa$ statistic was 0.86 (Pourshams et al, 2005). Data was collected on demographic variables, ethnicity, alcohol consumption, lifelong history of tobacco or opium use, medication, and several potential confounders.

\section{Serological data}

Prior to endoscopy, an experienced nurse collected $12 \mathrm{ml}$ venous blood sample from each case subject. A trained technician immediately separated serum and stored it at $-80^{\circ} \mathrm{C}$. Collected blood samples from matched controls were transferred on ice in a cooler box $\left(\sim 4^{\circ} \mathrm{C}\right)$. Time between collection and processing of neighbourhood control samples was $<12 \mathrm{~h}$. For those controls who were interviewed at the Golestan Cohort Centre, sample processing and storage were performed immediately. Samples were transported on dry ice to Karolinska Institutet, Sweden, and stored at $-20{ }^{\circ} \mathrm{C}$ prior to analysis. Serum pepsinogen I and II were measured blinded to case-control status using enzyme-linked immunosorbent assays (Biohit, Helsinki, Finland). Aliquots from a pool of serum samples of healthy individuals were distributed among nine assay plates (two samples per plate). The coefficients of variation were $8 \%$ and $14 \%$ for PGI and PGII, respectively. H. pylori serology was evaluated qualitatively with western blot assay (Helico Blot 2.1; MP Biomedicals Asia Pacific Ltd, Singapore, Singapore). $H$. pylori infection was considered positive if (1) both 19.5- and 30-kDa bands were present or (2) any of the 35-, 37-, or $89-\mathrm{kDa}$ band was present. CagA was positive if $116-\mathrm{kDa}$ band was present. We have carried out a validation study in the same population with similar ethnic structure among 309 endoscopy clinic patients and compared pepsinogen serology with histology using modified Sydney classification as the gold standard. We reported $\mathrm{PGI}<55 \mu \mathrm{gl}^{-1}$ (sensitivity: $61.9 \%$, specificity: $94.8 \%$ ) as the optimal cutoff point for serological diagnosis of gastric fundal atrophy in the study population. At cutoff concentration of $11.8 \mu \mathrm{gl}^{-1}$, PGII demonstrated $84.2 \%$ sensitivity and $45.4 \%$ specificity to distinguish nonatrophic pangastritis (Nasrollahzadeh et al, 2011).

\section{Statistical methods}

Serum PGI and PGII were analysed as dichotomous variables using validated cutoff points. There was no a priori DMFT cutoff value, and cubic spline curve did not highlight any specific pattern, therefore the median DMFT was considered as a cutoff value for dichotomising it. Conditional logistic regression models were used to calculate odds ratios (ORs) and 95\% confidence intervals (CIs). In design, case and control subjects were individually matched for age, sex, and place of residence. ORs were further adjusted for education, ethnicity (Turkmen vs non-Turkmen), tobacco and opium use, alcohol drinking, and fruit/vegetable consumption. Interaction on additive scale between dichotomous variables of gastric atrophy and poor dental health or oral hygiene habit was evaluated and the relative excess risk due to interaction (RERI), attributable proportion and synergy index were calculated. Delta method was applied to calculate $95 \%$ CI for measures of interaction. To address the effect of bias due to measurement error in serology assay, the ORs adjusted for misclassification as a function of different sensitivity and specificity for cases and controls were calculated using external validation data. Two-sided $P$-values $\leqslant 0.05$ were considered as statistically significant. All analyses were done using Stata version 11.1 (StataCorp., College Station, TX, USA).

\section{Ethical approval}

This study was approved by the ethical committee of the Digestive Disease Research Centre of Tehran University of Medical Sciences, Iran, the Institutional Review Board of National Cancer Institute, USA, and the Stockholm Regional Ethics Vetting Board, Sweden.

\section{RESULTS}

The study included 300 incident case patients and 571 matched control subjects from whom serum samples were available for $293(98 \%)$ cases and 524 (92\%) controls. All cases had at least one matched control. Demographic characteristics of the study participants and potential confounders are summarised in Table 1. No substantial differences were observed between those who provided serum and those whose serum samples were not available.

Table 2 demonstrates proportion of subjects with serological gastric atrophy and ORs for association of PGI and PGII with OSCC risk after further controlling for education level and ethnicity (as socioeconomic index), opium and tobacco use, fruit, vegetable, and alcohol consumption. A PGI $<55 \mu \mathrm{gl}^{-1}$ was 
Table I Characteristics of OSCC cases and matched controls, Golestan province, Iran, 2003-2007

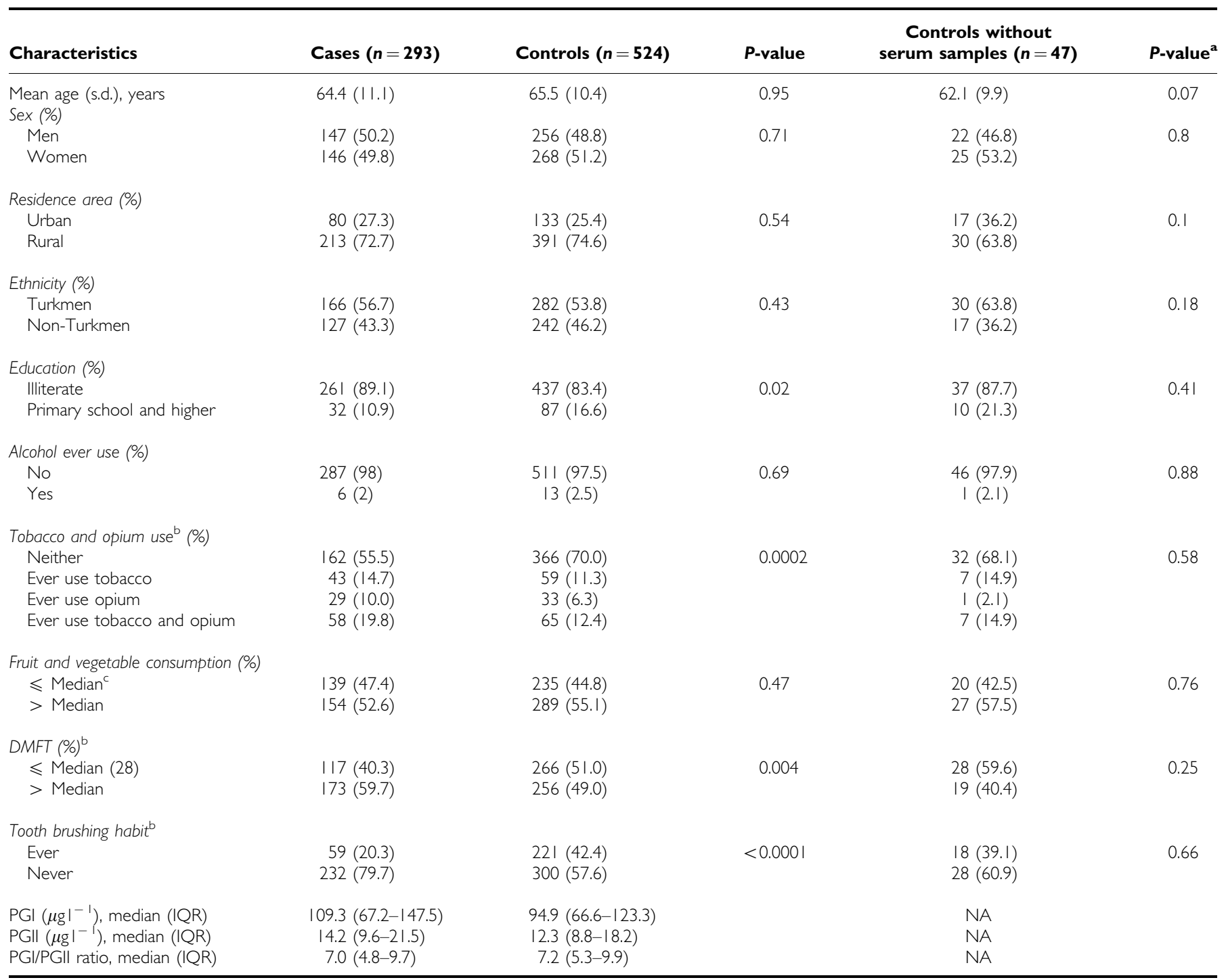

Abbreviations: DMFT = Sum of decayed, missed, and filled teeth; $I Q R=$ interquartile range; $N A=$ not applicable; OSCC = oesophageal squamous cell carcinoma. ${ }^{\text {a }}$-value for significance of difference between controls with and without serum samples. ${ }^{b}$ Numbers of cases and controls were less than total because of missed data. ${ }^{\mathrm{C}}$ Median fruit and vegetable consumption $=521.8 \mathrm{gr} /$ day.

associated with a 1.39-fold increased risk of OSCC (95\% CI: 0.93 , 2.09). Histological diagnosis of non-atrophic gastritis was found in $30 \%$ of OSCC cases with 2 -fold risk comparing clinic controls $(\mathrm{OR}=1.97,95 \% \mathrm{CI}: 1.13,3.45)$ (Supplementary Table). Because gastritis might be caused secondary to OSCC, we evaluated the association of gastric fundal atrophy with OSCC in combination with severe nonatrophic pangastritis. Combination of PGI $<55 \mu \mathrm{gl}^{-1}$ and PGII $<11.8 \mu \mathrm{gl}^{-1}$ was associated with a two-fold increased risk for OSCC. Further adjustment for tea-drinking habit as a suggested strong risk factor in this population (Islami et al, 2009) did not alter the observed estimates. H. pylori serology, measured as antibodies against either whole $H$. pylori or CagA, was not associated with OSCC risk.

We applied other published thresholds for atrophy, including PGI $<30 \mu \mathrm{gl}^{-1}$, PGI/PGII ratio $<3$ and PGI $<70 \mu \mathrm{g} 1^{-1}$, PGI/PGII ratio $<3$. The measures of association did not change materially. Combination with PGII also showed similar results (Table 3).

Table 4 presents the results of joint effect of gastric atrophy, poor dental health, and oral hygiene habit on OSCC risk after breaking the matching factors. Adjusted OR for association of DMFT with OSCC was 1.60 (95\% CI: 1.14, 2.24). Although based on modest numbers of cases, presence of poor dental hygiene, indicated as higher than median DMFT, and gastric atrophy rendered a more than four-fold excess risk of OSCC compared with the group with neither poor dental hygiene nor atrophy. The RERI between low DMFT and atrophy was 1.47 (95\% CI: - 1.15, 4.1), synergy index (95\% CI) $1.90(0.6,6.1)$, and the attributable proportion $(95 \% \mathrm{CI}) 0.36(-0.14,0.85)$. We used frequency of tooth brushing as another measure of dental and oral hygiene in combination with gastric atrophy, which resulted in an eight-fold increase in OSCC risk (OR: 8.65, 95\% CI: 3.65, 20.46) compared with non-atrophic group who occasionally or regularly brush their teeth. The RERI between habit of never brushing teeth and atrophy was 4.34 (95\% CI: - 1.07, 9.76), synergy index 2.24 (95\% CI: 0.97, 5.15 ), and attributable proportion 0.49 (95\% CI: $0.14,0.83$ ). Although based on fewer sets, conditional logistic regression model showed similar results (data not shown).

To quantify the magnitude of misclassification bias that occurs in presence of nonatrophic gastritis, we estimated the classification probabilities using external validation study (Nasrollahzadeh et al, 2011). Effects of the range of PGII levels on diagnostic accuracy of atrophy and corrected ORs for the association with OSCC are 
Gastric atrophy and oesophageal squamous cell carcinoma

D Nasrollahzadeh et al

Table 2 Levels of pepsinogen I, pepsinogen II, and H. pylori serology and their associations with OSCC risk, Golestan province, Iran, 2003-2007

\begin{tabular}{|c|c|c|c|c|}
\hline & Controls, $N$ (\%) & Cases, $N(\%)$ & Crude OR (95\% CI) & Adjusted OR $(95 \% \mathrm{CI})^{\mathrm{a}}$ \\
\hline \multicolumn{5}{|l|}{$P G I\left(\mu g I^{-1}\right)$} \\
\hline$\geqslant 55$ & $449(85.7)$ & $238(81.2)$ & Referent & Referent \\
\hline$<55$ & $75(14.3)$ & $55(18.8)$ & $1.33(0.89-1.97)$ & $1.39(0.93-2.09)$ \\
\hline \multicolumn{5}{|l|}{$P G \|^{\mathrm{b}}\left(\mu g I^{-1}\right)$} \\
\hline$<11.8$ & $246(46.9)$ & $113(38.7)$ & Referent & Referent \\
\hline$\geqslant 11.8$ & $278(53.1)$ & $179(63.1)$ & $1.37(1.01-1.85)$ & $1.40(1.01-1.92)$ \\
\hline \multicolumn{5}{|l|}{$P G I$ and $P G \|^{b}\left(\mu g I^{-1}\right)$} \\
\hline$P G \mid \geqslant 55$ and $P G \|<11.8$ & $189(36.1)$ & $7 \mid(24.2)$ & Referent & Referent \\
\hline PGI $<55$ and $P G \|<11.8$ & $57(10.9)$ & $42(14.3)$ & $1.92(1.15-3.22)$ & $2.01(1.18-3.45)$ \\
\hline$P G \mid \geqslant 55$ and $P G \| \geqslant 11.8$ & $260(49.6)$ & $167(57)$ & Referent & Referent \\
\hline$P G \mid<55$ and $P G \| \geqslant 11.8$ & $18(3.4)$ & $12(4.4)$ & $1.02(0.47-2.23)$ & $1.20(0.54-2.66)$ \\
\hline \multicolumn{5}{|l|}{ H. pylori status } \\
\hline H. pylori - cagA - & $52(10)$ & $35(12)$ & Referent & Referent \\
\hline H. pylori + cagA - & $34(6.5)$ & $14(4.8)$ & $0.64(0.30-1.35)$ & $0.70(0.32-1.53)$ \\
\hline H. pylori + cagA + & $351(67.2)$ & $179(6 \mid .3)$ & $0.73(0.46-1.17)$ & $0.79(0.48-1.29)$ \\
\hline H. pylori - cagA + & $85(16.3)$ & $64(21.9)$ & $1.05(0.60-1.85)$ & $1.15(0.63-2.08)$ \\
\hline
\end{tabular}

Abbreviations: cagA = cytotoxin-associated gene $\mathrm{A} ; \mathrm{Cl}=$ confidence interval; $\mathrm{H}$. pylori= Helicobacter pylori; OR = odds ratio; OSCC = oesophageal squamous cell carcinoma; PGI = pepsinogen I; PGII = pepsinogen II. aAdjusted for ethnicity (Non-Turkmen or Turkmen), alcohol consumption (never or ever), tobacco or opium use (none, only tobacco,

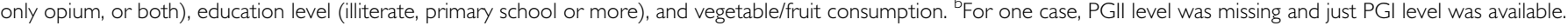

Table 3 Gastric atrophy defined by other serology criteria in literature and its association with OSCC risk

\begin{tabular}{|c|c|c|c|}
\hline & Controls, $N(\%)$ & Cases, $N(\%)$ & Adjusted OR $(95 \% \mathrm{CI})^{\mathrm{a}}$ \\
\hline \multicolumn{4}{|l|}{ PGl } \\
\hline$P G \mid \geqslant 30$ & $500(95.4)$ & $274(93.5)$ & Referent \\
\hline$P G \mid<30$ & $24(4.6)$ & $19(6.5)$ & $1.52(0.79-2.93)$ \\
\hline \multicolumn{4}{|l|}{ Stratifying by PGIl level ${ }^{b}$} \\
\hline$P G \mid \geqslant 30$ and $P G \|<11.8$ & $226(43.1)$ & $97(33.1)$ & Referent \\
\hline$P G \mid<30$ and $P G \|<11.8$ & $4(0.8)$ & $3(1.0)$ & $1.94(0.9 \mid-4.13)$ \\
\hline$P G \mid \geqslant 30$ and $P G \| \geqslant 11.8$ & $274(52.3)$ & $176(60.4)$ & Referent \\
\hline$P G \mid<30$ and $P G \| 1 \geqslant 11.8$ & $20(3.8)$ & $16(5.5)$ & $1.10(0.23-5.17)$ \\
\hline \multicolumn{4}{|l|}{ PGI/PGIl ratio ${ }^{b}$} \\
\hline Ratio $\geqslant 3$ & $490(93.5)$ & $265(90.8)$ & Referent \\
\hline Ratio $<3$ & $34(6.5)$ & $27(9.2)$ & $1.50(0.85-2.60)$ \\
\hline \multicolumn{4}{|l|}{ Stratifying by $P G \mid l$ level ${ }^{b}$} \\
\hline Ratio $\geqslant 3$ and PG\| $<11.8$ & $233(44.5)$ & $100(34.1)$ & Referent \\
\hline Ratio $<3$ and $P G \|<11.8$ & $21(4.0)$ & $14(4.8)$ & $2.32(1.00-5.39)$ \\
\hline Ratio $\geqslant 3$ and PG $\| \geqslant 11.8$ & $257(49.0)$ & $165(56.7)$ & Referent \\
\hline Ratio $<30$ and $P G \| \geqslant 11.8$ & $13(2.5)$ & $13(4.4)$ & $1.03(0.49-2.20)$ \\
\hline \multicolumn{4}{|l|}{ PGl and PGI/PGIl ratio ${ }^{b}$} \\
\hline$P G \mid \geqslant 70$ or ratio $\geqslant 3$ & 497 (94.9) & $267(91.5)$ & Referent \\
\hline $\mathrm{PGl}<70$ and ratio $<3$ & $27(5.1)$ & $25(8.5)$ & $1.69(0.93-3.10)$ \\
\hline \multicolumn{4}{|l|}{ Stratifying by $P G \mid l$ level ${ }^{b}$} \\
\hline$(P G \mid \geqslant 70$ or ratio $\geqslant 3)$ and $P G \|<11.8$ & $233(44.5)$ & $100(34.19)$ & Referent \\
\hline$(P G \mid<70$ and ratio $<3)$ and $P G \|<11.8$ & $14(2.6)$ & $12(4.1)$ & $2.31(0.99-5.38)$ \\
\hline$(P G \mid \geqslant 70$ or ratio $\geqslant 3)$ and $P G \| \geqslant 11.8$ & $264(50.4)$ & $167(57.4)$ & Referent \\
\hline$(P G \mid<70$ and ratio $<3)$ and $P G \| \geqslant 11.8$ & $13(2.5)$ & $13(4.4)$ & $1.24(0.52-2.94)$ \\
\hline
\end{tabular}

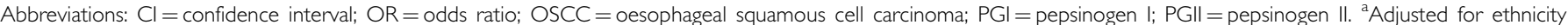
(Non-Turkmen or Turkmen), alcohol consumption (never or ever), tobacco or opium use (none, only tobacco, only opium, or both), education level (illiterate, primary school or more), and vegetable/fruit consumption. ${ }^{b}$ For one case, PGIl level was missing and just PGI level was available.

presented in Table 5. Differential misclassification of gastric atrophy for cut points with low specificity $(<80 \%)$ was far from the null. When exposure detection was better among controls, the resulted OR was extensively biased.

\section{DISCUSSION}

In this study, gastric atrophy, as indicated by low serum pepsinogen, was associated with an increased risk of OSCC. 
Table 4 Combined effects of gastric atrophy and dental health or oral hygiene habit on OSCC risk after breaking the matching factors

\begin{tabular}{|c|c|c|c|c|}
\hline & \multicolumn{2}{|c|}{ Gastric atrophy - } & \multicolumn{2}{|c|}{ Gastric atrophy +} \\
\hline DMFT > 28 & $40 / 84$ & $\begin{array}{c}\text { I.7। }(0.98-2.98) \\
P=0.06\end{array}$ & $30 / 31$ & $\begin{array}{c}3.47(1.81-6.64) \\
P<0.001\end{array}$ \\
\hline Ever tooth brushing & $14 / 87$ & Referent & $5 / 24$ & $\begin{array}{c}1.40(0.44-4.39) \\
P=0.57\end{array}$ \\
\hline
\end{tabular}

Abbreviations: $\mathrm{Cl}=$ confidence interval; DMFT $=$ sum of decayed, missed, and filled teeth; $\mathrm{OR}=$ odds ratio; OSCC = oesophageal squamous cell carcinoma. Measure of interaction on additive scale: relative excess risk due to interaction with low DMFT ( $95 \% \mathrm{Cl}$ ): $1.47(-1.15$ to 4.1$)$ and with never tooth brushing habit $(95 \% \mathrm{Cl})$ : 4.34 $(-1.07$ to 9.76). Measure of interaction on multiplicative scale: between atrophy and low DMFT: OR $(95 \% \mathrm{Cl})$ : $1.44(0.63-3.32) ; P=0.39$ and measure of interaction between atrophy and never tooth brushing on multiplicative scale: $\mathrm{OR}(95 \% \mathrm{Cl})$ : $1.78(0.30-10.42) ; \mathrm{P}=0.52 .{ }^{\mathrm{a}} \mathrm{ORs}(95 \% \mathrm{Cl})$ levels adjusted for age, sex, residence area, ethnicity (Non-Turkmen or Turkmen), alcohol consumption (never or ever), tobacco or opium use (none, only tobacco, only opium, or both), education level (illiterate, primary school or more), and vegetable/fruit consumption.

Table 5 Gastric atrophy defined by PGI $<\left.55 \mu \mathrm{g}\right|^{-1}$ and its association with OSCC risk under assumption of various sensitivity (se) and specificity (sp) among cases and controls

\begin{tabular}{|c|c|c|c|c|c|c|c|c|c|}
\hline & & & $\begin{array}{l}\text { Controls } \\
\text { All PGII } \\
\text { Se: } 0.62 \\
\text { Sp: } 0.95\end{array}$ & $\begin{array}{c}\text { Only PGII }<5 \\
0.99 \\
0.68\end{array}$ & $\begin{array}{c}\text { Only PGII }<I I .8 \\
0.83 \\
0.89\end{array}$ & $\begin{array}{c}\text { Only PGII }<15 \\
0.80 \\
0.91\end{array}$ & $\begin{array}{c}\text { Only PGII }<19 \\
0.80 \\
0.92\end{array}$ & $\begin{array}{c}\text { Only PGII }<30 \\
0.76 \\
0.94\end{array}$ & $\begin{array}{c}\text { Only PGII > I I.8 } \\
0.37 \\
0.98\end{array}$ \\
\hline Cases & Se & Sp & & & & & & & \\
\hline All PG\|l & 0.62 & 0.95 & 1.63 & $\mathrm{a}$ & 6.6 & 3.9 & 3.3 & 2.4 & 0.59 \\
\hline Only PGII $<15$ & 0.80 & 0.91 & 0.8 & a & 3.3 & 1.97 & 1.7 & 1.2 & 0.3 \\
\hline Only PGII $<19$ & 0.80 & 0.92 & 0.9 & $\mathrm{a}$ & 3.6 & 2.2 & 1.83 & 1.3 & 0.3 \\
\hline Only PGII $<30$ & 0.76 & 0.94 & 1.1 & $\mathrm{a}$ & 4.6 & 2.8 & 2.3 & 1.65 & 1.66 \\
\hline Only PG\| $>11.8$ & 0.37 & 0.98 & 4.7 & $\mathrm{a}$ & 19.1 & 11.4 & 9.6 & 6.8 & 1.69 \\
\hline
\end{tabular}

Abbreviations: OSCC = oesophageal squamous cell carcinoma; PGI = pepsinogen I; PGII= pepsinogen II. ORs are adjusted for age, sex, and residence area in unconditional logistic regression model. ${ }^{\text {T}}$ These cells yielded negative adjusted counts, which were impossible values for true counts, thus corrected ORs could not be estimated.

Pepsinogens are markers of mixed conditions, including gastritis and atrophy (He et al, 2011), which could be of distinct etiologies in cancer patients. In spite of observed association between serological nonatrophic pangastritis with OSCC in our study, the probability of developing gastritis secondary to oesophageal cancer is not ignorable because of several evidences. Most importantly, studies with cohort design did not detect significant association between PGII and OSCC risk. In addition, cancer patients may develop gastritis due to non-steroidal antiinflammatory drug (NSAID) use, opportunistic infections in stomach (cytomegalovirus, Epstein-Barr virus), malnutrition, anaemia, and consequent use of iron tablets (Abraham et al, 1999; Lauwers et al, 2010). Stage of tumours in most of our study population were III or IV at the time of diagnosis, and dysphagia was the presenting symptom, which led to high proportion of NSAID consumption among cases compared with controls (24.7\% vs $15.8 \%, P=0.001)$. On the other hand, development of marked atrophy needs long time period (Adamu et al, 2011) and its initiation during OSCC progression with short lead time is unlikely. Thus, in studying the relationship between gastric atrophy and OSCC when serum collection period is close to cancer diagnosis, PGI provides more valid estimate than PGI/PGII ratio.
Low sensitivity for atrophy detection might lead to loss of precision and power by unnecessarily reducing the exposed sample size. We chose atrophy cutoff point at high specificity level (97\%) however, false negative probability of 0.4 and low prevalence of gastric atrophy could potentially result in misclassification of exposure among cases and controls. Which we believe, if evolves, would be differential.

Histology is the gold standard for atrophy diagnosis, however, detection of atrophy is difficult because of the limitation in number of biopsies and patchy nature of atrophy. Furthermore, mucosal inflammation and separation of glands by inflammatory infiltrate would add more diagnostic difficulties in severe gastritis (Owen, 2003). Because inflammation among our cancer patients was more probable than healthy controls, the error probabilities for unexposed cases and controls might not be identical. To decrease the effect of mixed category and to reduce the problem of non-identical false-negative probabilities, we stratified the presence of nonatrophic pangastritis and observed a two-fold increased OSCC risk associated with atrophy.

Notably, reducing interpretations to a dichotomy could degrade the information. False-negative results are inherent in serological diagnosis of atrophy due to the low sensitivity of the diagnostic method. It is believed that resulted misclassification will drive the 
association toward null if non-differential assumptions are met. However, atrophy is an uncommon exposure and its binary value is the result of categorising continuous PGI variable. Therefore, we performed a sensitivity analysis with the external validation data. Our results confirmed that the effect of misclassification due to ignoring nonatrophic pangastritis on association between atrophy and OSCC was substantial. This finding suggests that PGII as a marker of severe inflammation could be used as a stratifying factor.

In this study, we could not detect any association between infection with $\operatorname{cagA} A$-positive $H$. pylori strains and OSCC risk, which is in contrast to the results from the study among low-risk Swedish population (Ye et al, 2004), Japanese alcoholic males (Yokoyama et al, 2009), and in accordance to the reports from studies in Linxian of China (Kamangar et al, 2007), Magdeburg of Germany (Venerito et al, 2011), and among Finnish male smokers (Cook et al, 2010). Spontaneous disappearance of $H$. pylori over time or $H$. pylori eradication is possibly common in endemic areas. Acquired immunodeficiency among advanced malnourished cancer patients could be another explanation for reduced immune response to antigens. These possibilities could lead to heterogeneity of $H$. pylori-negative category as a reference. Hence, our risk estimates for $H$. pylori and CagA infection are inconclusive because of difficulties in achieving a clean reference group in an endemic area for $H$. pylori infection and among aged population in a case-control design.

Our study might indicate areas to search for the underlying mechanism. There was a suggestive evidence that the estimated joint effect of poor dental health or never tooth brushing and gastric atrophy together was larger than the sum of their effects alone, which is in favour of the hypothesis of the bacterial overgrowth in atrophic stomach and low-hygiene periodontal mucosa (Meurman and Bascones-Martinez, 2011). Endogenous formation of nitrosamines in the oral cavity of those with poor oral hygiene is eightfold higher than that in those with good oral hygiene (Nair et al, 1996). Upstream microbial community members from the oral mucosa and oesophagus have the potential to translocate to the stomach, and they might act as reservoirs for recolonisation. Gastric microbiota shows considerable overlap with oral microbiota (Bik et al, 2006), however, the mechanism of these two bacterial environment in OSCC carcinogenesis could be

\section{REFERENCES}

Abnet CC, Kamangar F, Islami F, Nasrollahzadeh D, Brennan P, Aghcheli K, Merat S, Pourshams A, Marjani HA, Ebadati A, Sotoudeh M, Boffetta P, Malekzadeh R, Dawsey SM (2008) Tooth loss and lack of regular oral hygiene are associated with higher risk of esophageal squamous cell carcinoma. Cancer Epidemiol Biomarkers Prev 17(11): 3062-3068

Abnet CC, Qiao YL, Mark SD, Dong ZW, Taylor PR, Dawsey SM (2001) Prospective study of tooth loss and incident esophageal and gastric cancers in China. Cancer Causes Control 12(9): 847-854

Abnet CC, Zheng W, Ye W, Kamangar F, Ji BT, Persson C, Yang G, Li HL, Rothman N, Shu XO, Gao YT, Chow WH (2011) Plasma pepsinogens, antibodies against Helicobacter pylori, and risk of gastric cancer in the Shanghai Women's Health Study Cohort. Br J Cancer 104(9): 1511-1516

Abraham SC, Yardley JH, Wu TT (1999) Erosive injury to the upper gastrointestinal tract in patients receiving iron medication: an underrecognized entity. Am J Surg Pathol 23(10): 1241-1247

Adamu MA, Weck MN, Rothenbacher D, Brenner H (2011) Incidence and risk factors for the development of chronic atrophic gastritis: five year follow-up of a population-based cohort study. Int J Cancer 128(7): 1652-1658

Bik EM, Eckburg PB, Gill SR, Nelson KE, Purdom EA, Francois F, Perez-Perez G, Blaser MJ, Relman DA (2006) Molecular analysis of the bacterial microbiota in the human stomach. Proc Natl Acad Sci USA 103(3): 732-737

Cook MB, Dawsey SM, Diaw L, Blaser MJ, Perez-Perez GI, Abnet CC, Taylor PR, Albanes D, Virtamo J, Kamangar F (2010) Serum pepsinogens and different. Our statistical inference on the presence of interaction between poor oral hygiene and gastric atrophy has less precision than the main finding of the study because of the modest sample size. The observed interaction might be due to other mechanisms, as tooth loss may be an indicator of a less healthy life style. However, we did not detect association between education as a socioeconomic status indicator and DMFT in our data. Also, low DMFT could be a marker for distinct diet because of reduced masticatory ability, hence, the detected association might be due to residual confounding.

This study was a population-based study, matching improved statistical efficiency, and sample size was the largest among the studies so far published. Markers of the main exposure and confounders were validated and extensive information on cofounders was available.

In conclusion, our population-based case-control study confirms that gastric atrophy is a risk factor for OSCC in high-risk area of northern Iran. Excluding nonatrophic pangastritis through stratifying by PGII level decreases the possibility of PGI misclassification due to cancer-induced inflammation. Gastric atrophy and poor oral hygiene may act synergistically in increasing the risk of OSCC.

\section{ACKNOWLEDGEMENTS}

We thank the local health network workers (Behvarz) for their contribution to this study. This work was supported by Digestive Disease Research Centre of Tehran University of Medical Sciences (Grant 82-603), Swedish Research Council (VR- 60535801), intramural funds of the National Cancer Institute at the National Institutes of Health, Martin Rinds Foundation (Sweden), and KID grant, Karolinska Institutet faculty funds for postgraduate students (December 2008).

\section{Conflict of interest}

The authors declare no conflict of interest.

Supplementary Information accompanies the paper on British Journal of Cancer website (http://www.nature.com/bjc)
Helicobacter pylori in relation to the risk of esophageal squamous cell carcinoma in the alpha-tocopherol, beta-carotene cancer prevention study. Cancer Epidemiol Biomarkers Prev 19(8): 1966-1975

de Vries AC, Capelle LG, Looman CW, van Blankenstein M, van Grieken NC, Casparie MK, Meijer GA, Kuipers EJ (2009) Increased risk of esophageal squamous cell carcinoma in patients with gastric atrophy: independent of the severity of atrophic changes. Int J Cancer 124(9): 2135-2138

He CY, Sun LP, Gong YH, Xu Q, Dong NN, Yuan Y (2011) Serum pepsinogen II: a neglected but useful biomarker to differentiate between diseased and normal stomachs. J Gastroenterol Hepatol 26(6): 1039-1046

Iijima K, Koike T, Abe Y, Inomata Y, Sekine H, Imatani A, Nakaya N, Ohara S, Shimosegawa T (2007) Extensive gastric atrophy: an increased risk factor for superficial esophageal squamous cell carcinoma in Japan. Am J Gastroenterol 102(8): 1603-1609

Islami F, Pourshams A, Nasrollahzadeh D, Kamangar F, Fahimi S, Shakeri R, Abedi-Ardekani B, Merat S, Vahedi H, Semnani S, Abnet CC, Brennan P, Moller H, Saidi F, Dawsey SM, Malekzadeh R, Boffetta P (2009) Tea drinking habits and oesophageal cancer in a high risk area in northern Iran: population based case-control study. BMJ 338: b929

Jemal A, Bray F, Center MM, Ferlay J, Ward E, Forman D (2011) Global cancer statistics. CA Cancer J Clin 61(2): 69-90

Kamangar F, Qiao YL, Blaser MJ, Sun XD, Katki H, Fan JH, Perez-Perez GI, Abnet CC, Zhao P, Mark SD, Taylor PR, Dawsey SM (2007) Helicobacter 
pylori and oesophageal and gastric cancers in a prospective study in China. Br J Cancer 96(1): 172-176

Lauwers GY, Fujita H, Nagata K, Shimizu M (2010) Pathology of nonHelicobacter pylori gastritis: extending the histopathologic horizons. J Gastroenterol 45(2): 131-145

Mahboubi E, Kmet J, Cook PJ, Day NE, Ghadirian P, Salmasizadeh S (1973) Oesophageal cancer studies in the Caspian Littoral of Iran: the Caspian cancer registry. Br J Cancer 28(3): 197-214

Malekshah AF, Kimiagar M, Saadatian-Elahi M, Pourshams A, Nouraie M, Goglani G, Hoshiarrad A, Sadatsafavi M, Golestan B, Yoonesi A, Rakhshani N, Fahimi S, Nasrollahzadeh D, Salahi R, Ghafarpour A, Semnani S, Steghens JP, Abnet CC, Kamangar F, Dawsey SM, Brennan P, Boffetta P, Malekzadeh R (2006) Validity and reliability of a new food frequency questionnaire compared to $24 \mathrm{~h}$ recalls and biochemical measurements: pilot phase of Golestan cohort study of esophageal cancer. Eur J Clin Nutr 60(8): 971-977

Meurman JH, Bascones-Martinez A (2011) Are oral and dental diseases linked to cancer? Oral Dis 17(8): 779-784

Meurman JH, Uittamo J (2008) Oral micro-organisms in the etiology of cancer. Acta Odontol Scand 66(6): 321-326

Millonig G, Wang Y, Homann N, Bernhardt F, Qin H, Mueller S, Bartsch H, Seitz HK (2011) Ethanol-mediated carcinogenesis in the human esophagus implicates CYP2E1 induction and the generation of carcinogenic DNA-lesions. Int J Cancer 128(3): 533-540

Nair J, Ohshima H, Nair UJ, Bartsch H (1996) Endogenous formation of nitrosamines and oxidative DNA-damaging agents in tobacco users. Crit Rev Toxicol 26(2): 149-161

Nasrollahzadeh D, Aghcheli K, Sotoudeh M, Shakeri R, Persson EC, Islami F, Kamangar F, Abnet CC, Boffetta P, Engstrand L, Dawsey SM, Malekzadeh R, Ye W (2011) Accuracy and cut-off values of pepsinogens I, II and gastrin 17 for diagnosis of gastric fundic atrophy: influence of gastritis. Plos One 6(10): e26957

Nasrollahzadeh D, Kamangar F, Aghcheli K, Sotoudeh M, Islami F, Abnet CC, Shakeri R, Pourshams A, Marjani HA, Nouraie M, Khatibian M, Semnani S, Ye W, Boffetta P, Dawsey SM, Malekzadeh R (2008) Opium, tobacco, and alcohol use in relation to oesophageal squamous cell carcinoma in a high-risk area of Iran. Br J Cancer 98(11): 1857-1863
National Toxicology Program (2010) Final report on carcinogens background document for formaldehyde. Rep Carcinog Backgr Doc (10-5981): i-512

Owen DA (2003) Gastritis and carditis. Mod Pathol 16(4): 325-341

Pourshams A, Saadatian-Elahi M, Nouraie M, Malekshah AF, Rakhshani N, Salahi R, Yoonessi A, Semnani S, Islami F, Sotoudeh M, Fahimi S, Sadjadi AR, Nasrollahzadeh D, Aghcheli K, Kamangar F, Abnet CC, Saidi F, Sewram V, Strickland PT, Dawsey SM, Brennan P, Boffetta P, Malekzadeh R (2005) Golestan cohort study of oesophageal cancer: feasibility and first results. Br J Cancer 92(1): 176-181

Ren JS, Kamangar F, Qiao YL, Taylor PR, Liang H, Dawsey SM, Liu B, Fan JH, Abnet CC (2009) Serum pepsinogens and risk of gastric and oesophageal cancers in the General Population Nutrition Intervention Trial cohort. Gut 58(5): 636-642

Saidi F, Sepehr A, Fahimi S, Farahvash MJ, Salehian P, Esmailzadeh A, Keshoofy M, Pirmoazen N, Yazdanbod M, Roshan MK (2000) Oesophageal cancer among the Turkomans of northeast Iran. $\mathrm{Br} J$ Cancer 83(9): 1249-1254

Venerito M, Kohrs S, Wex T, Adolf D, Kuester D, Schubert D, Peitz U, Monkemuller K, Malfertheiner P (2011) Helicobacter pylori infection and fundic gastric atrophy are not associated with esophageal squamous cell carcinoma: a case-control study. Eur J Gastroenterol Hepatol 23(10): 859-864

Viani F, Siegrist HH, Pignatelli B, Cederberg C, Idstrom JP, Verdu EF, Fried M, Blum AL, Armstrong D (2000) The effect of intra-gastric acidity and flora on the concentration of N-nitroso compounds in the stomach. Eur J Gastroenterol Hepatol 12(2): 165-173

Ye W, Held M, Lagergren J, Engstrand L, Blot WJ, McLaughlin JK, Nyren O (2004) Helicobacter pylori infection and gastric atrophy: risk of adenocarcinoma and squamous-cell carcinoma of the esophagus and adenocarcinoma of the gastric cardia. J Natl Cancer Inst 96(5): 388-396

Yokoyama A, Omori T, Yokoyama T, Kawakubo H, Mori S, Matsui T, Maruyama K (2009) Chronic atrophic gastritis and metachronous gastric cancer in Japanese alcoholic men with oesophageal squamous cell carcinoma. Alcohol Clin Exp Res 33(5): 898-905

This work is published under the standard license to publish agreement. After 12 months the work will become freely available and the license terms will switch to a Creative Commons Attribution-NonCommercial-Share Alike 3.0 Unported License. 